\title{
Local content production and the political economy of the mobile app industries in Argentina and Bolivia
}

\author{
Sarah Wagner and Mireia Fernández-Ardèvol \\ Open University of Catalonia, Spain
}

\begin{abstract}
Mobile broadband is playing an increasingly important role in the developing world. However, mobile platform providers and app publishers are dominated by multinational companies headquartered in the West. Where international agendas commit to promote local content production and a culturally diverse information society, there is minimal research on the orientation of commercial app production in developing regions. This article examines the targets and activities of mobile app developers in two Latin American economies - Argentina and Bolivia - analysing the political, social and economic conditions that connect or disconnect app developers and the interests of local users. Findings suggest that app distribution platforms do not favour local markets and that app developers largely focus on custom-design projects for commercial firms.
\end{abstract}

\section{Keywords}

App developers, app distribution, app stores, Latin America, local content production, media democratisation, mobile app industry, mobile communication and development, mobile media, political economy 


\section{Introduction}

Beyond concerns of digital access divides or even use divides, some recent mobile communication and development studies consider the local relevance of mobile services and how they influence quality of use. For example, French designed mobile services can cause cross-cultural issues for West-African immigrants (Bationo-Tillon et al., 2014) and literacy levels or language has been found to reduce phone usability among farmers in Bangladesh (Dey et al., 2011). This paper contributes a new angle to research on the local relevance of mobile communication by considering the power structures behind mobile app production that distance user groups from available services. Political economy analyses of communication media are not new (e.g. Bolaño \& Mastrini, 2001; Mansell, 2004) and typically concern arrangements of power in media systems, looking at the role of public policies and market structures in shaping contents and their distribution. As the mobile phone is increasingly used as a gateway to the Internet and to produce and exchange information (Donner, 2010), we argue it is important to consider the orientation of the apps which enable these activities, particularly in regions where users are culturally removed from the hubs of mobile media production. We zone in on commercial mobile app developers in two Latin American economies-Argentina and Bolivia—as a lens to analyse the app industry structure, considering the political, social and economic conditions that connect or disconnect developers and user interests.

While mobile apps produced for development aid initiatives have been researched in numerous contexts (see Kumar and Svensson, 2012; Niang et al., 2014), few studies 
consider the orientation of commercial app production from a social development perspective. Exceptions include bottom of the pyramid analyses of mobile money transfer services (e.g. Ngugi et al., 2010), a review of mobile apps developed in East Africa (Hellström, 2010) and a recent report on the Indian app ecosystem (Kathuria and Srivastav, 2014). Moreover, in Latin America, compared to Africa or Asia, there is minimal research on the social or development implications of mobile apps in general. ${ }^{1}$ Where the mobile subscription rate in low and middle-income countries in Latin America and the Caribbean in 2012 outnumbered the global average (109 vs. 89 per hundred habitants respectively) (own calculation based on ITU, 2013a), this is a significant gap in the research.

\section{Background}

\section{Media politics and local content production}

Critical perspectives on the power asymmetries of media production arose in the 1970s and drew attention to the dominance of transnational media corporations (Fejes, 1981). The Americanisation and marketisation of media was revealed as imperialistic, perpetuating the economic and social domination of the global North (e.g. Beltrán \& Fox de Cardona, 1980; Mattelart, 1974). Influenced by economic dependency theory, and Latin American scholarship in particular (Bolaño \& Mastrini, 2001: 68), the 1980 UNESCO commissioned 'MacBride Report' documented the imbalanced flow of communication media and set out principles for a New World Information and Communication Order (NWICO). The NWICO was never successfully implemented, being overrun by dominant ideologies of deregulation and privatisation on the backdrop of lobbying by the World Trade 
Organisation (Mastrini, 2005). Yet, it raised important debates on the top-down structure of media dissemination and the exclusion of developing world populations. In effect, the local and non-commercial production of contents became envisaged as key to media democratisation (Rodríguez, 2010).

The World Summits on the Information Society (WSIS) in the early 2000s revisited media democratisation, this time concerning digitised information in general. Critics point to the WSIS' failure to carry forth the structural changes called for by the NWICO in their alignment with neoliberal values of free-flowing information and prioritisation of access over participation in production (Mastrini, 2005; Pickard, 2007). Yet, the summits brought together varied stakeholder groups (see Padovani \& Tuzzi, 2004) and affirmed commitments to localise content production. The Tunis Agenda calls for supporting 'local producers of cultural content and applications' (WSIS, 2005: 5) and 'enhancing the capacity of communities in all regions to develop content in local and/or indigenous languages' (WSIS, 2005: 14).

While political economy perspectives on communication 'dried up' in the 1990s in North American academic circles (McChesney qtd. in Schwartz, 2014: 175), political activism and the examination of media conglomerates has remained main-stage in Latin American scholarship (e.g. de Valle Rojas, 2009; Martín-Barbero, 2002; Mastrini \& Becerra, 2011), at times influencing national policies (Bolaño \& Mastrini, 2001: 75). During the last decade, media regulations in a number of Latin American countries have tended towards 
democratisation through the localisation of content production: corporate monopolisations are restricted through frequency allocations to non-profit or public sectors and quotas of content must be produced nationally or locally. Such regulations have focused on television and radio broadcasting (Author), and public policies generally have allotted minimal attention to new media production and management processes (cf. Goggin, 2011: 179).

A fair amount of optimism has been expressed about the democratising potential of horizontal sharing platforms enabled by new media (Loader and Mercea, 2011): mainstream media has been contested (Moyo, 2007), marginalised groups have attained voice and counter-hegemonic social movements have been facilitated (Castells, 2012). However, the extent to which user productions on the Internet can be considered democratic or participatory is a debated issue. Aside from inequalities relating to access and digital literacy, critics have pointed to the commercial orientation of many online sharing sites. While the Internet emerged from an academic adventure aimed at building an open, decentralised network (Castells, 2001), in recent years Internet use centres on for-profit Web 2.0 sites (cf. Zittrain, 2008): in May 2014 Alexa calculated that the top five sites in terms of number of visitors and page-views were Google, Facebook, YouTube, Yahoo and Baidu, all for-profit corporations.

The corporate monopoly of internet sharing platforms has raised two main sorts of concerns. First, the overarching financial aim of websites results in user disempowerment: user traffic is about advertising revenue-site managers collect and sell data on user 
profiles but are not interested in the content of user contributions (Jenkins et al., 2013). In this sense media may be posted—or voiced—from a multitude of sources but their contents and political force are often ignored, lost through filtering mechanisms which prioritise commercial ends (Fuchs, 2009; Hindman, 2009). Second, the structure of sharing platforms is rooted in the cultural assumptions of the producers or managers, shaping the manner in which users interact and share contents. As cultural practices of communication and spatiotemporal organisation vary significantly, Srinivasan (2012) argues that the monopolisation of social media technologies by Western knowledge structures may impose on users in developing contexts and reaffirm existing social and economic inequalities.

\section{The mobile app ecosystem}

The wide variety of media retrieved—or produced—over mobile handsets, from FM radio contents to Web 2.0 sharing sites, are increasingly managed and accessed via apps. A recent study in the United States found iOS and Android users spending 86\% of their devicebased time within apps (Khalaf, 2014). While the mobile is an increasingly important gateway to the Internet, studies suggest the experience of mobile internet is more restricted than PC internet (Walton and Donner, 2012). The proprietary mobile service structure is often contrasted with the 'open' Internet structure, where mobile contents and services are 'locked in’ with service providers (Goggin, 2011; Gurumurthy, 2010). Concerns with the 'appliancization' (Zittrain, 2008) of the Internet and the prominence of commercially managed platforms discussed above are particularly relevant to the mobile ecosystem. The structure and contents of Internet web sites are often altered when accessed by mobile 
devices. Moreover, processes of producing, distributing and receiving mobile contents depend on affordances granted by platform providers. Traditionally, network providers managed most aspects of mobile services, but with the popularisation of smartphones, platform providers are now in the position of power, with stronghold over the contents and the underlying software (Basole and Karla, 2012).

Two companies based in United States_-Google and Apple-monopolise smartphone platform provision, holding 93\% of the global market share as of mid-2013 (IDC, 2013). In addition, they provide the largest platforms for app distribution, where Google's Android Playstore and Apple's iOS App Store had each accumulated over 50 billion downloads by 2013 (Statista, 2014). Apple maintains complete control over iOS native apps. Developers must be licensed by Apple and are restricted in app distribution. With a US $\$ 99$ per year license, developers in most countries—including Argentina and Bolivia—can post and sell apps on the iOS Store, subject to approval by Apple, or they can share apps with up to 100 iOS devices. The only other way Apple allows iOS apps to be distributed is directly to companies for in-house use, requiring an annual license fee of US\$299 (Apple, 2014). Google does not restrict the distribution of Android apps but developers wishing to post apps on the Playstore must register and pay a one-time fee of US\$25. Developers in nearly all regions can post free apps on the Playstore but sales through Google's merchant registration are limited to 45 countries, primarily covering North America, Europe and East Asia. At the time of writing, this list did not include any countries in Africa and only three 
in Latin America-Mexico, Brazil and Argentina (Google, 2014). The architecture of the iOS and Android app stores supports the popularisation of apps published by large corporations in the United States, such as Google and Facebook, as can be seen in Table 1.

\section{Objective and method}

The main aim of this research is to explore the perspectives and activities of mobile app developers in Argentina and Bolivia. What incentives or impediments are there for targeting the national or foreign app markets? Under what circumstances do developers market apps to general public users within their own country? What types of clients are important for developers and what is the role of online app stores? Research results intend to generate hypotheses on the social, economic and political conditions that connect or disconnect app developers and the interests of local user groups. In this sense, we adopt a political economy approach along the lines of Mansell's characterisation: 'a political economy of new media insists on examination of the circumstances that give rise to any given distribution of power and of the consequences for consumers and citizens' (2004: 5). While the direct consequences for users are not the subject of this study, we suggest that the diversification and localisation of mobile app production is important for the cultural relevance and social equity of mobile communication. We focus on the circumstances that shape the targets of app developers, paying particular attention to the manner in which innovation and distribution processes commodify, internationalise or localise developers' activities. 
Data is collected from two sources: the content analysis of 195 mobile app firm websites and 18 semi-structured interviews with app developers and related practitioners. Corporate website analysis has been used across disciplines to gather information on firms' activities (e.g. Meroño-Cerdan and Soto-Acosta, 2005), target audiences (e.g. Hwang et al., 2003) or social orientation (e.g. Snider et al, 2003), and mixed-methods research is a well-adopted strategy to increase the validity and richness of the analysis (see Greene et al, 1989). In this study, the qualitative interview data provides context and further insight into the targets and activities accounted in the quantitative website analysis.

The website review was conducted in two phases: a pilot study in the first half of 2013 and a final review in April 2014. For each country, we produced a list of commercial firms which have functioning websites and which explicitly claim to develop mobile apps. While we do not claim that these lists are exhaustive, we aimed at saturation, using a combination of online directories, internet search engines, social and business networking sites, participant referrals and the lists of entities associated with Argentina's Chamber of Software and Information Services Businesses and Bolivia's Chamber of Information Technology. In total, 157 websites in Argentina and 38 websites in Bolivia were identified. During the pilot study, approximately one third of the identified websites were reviewed through which we fine-tuned the dimensions of study. In the final study, all identified websites were reviewed. Table 2 provides an overview of the reviewed dimensions. 
The semi-structured interviews, outlined in Table 3, were conducted over Skype and recorded for posterior analysis. No preferential selection was used to identify app developers. Interview requests were sent to 63 commercial firms identified through the pilot website review. The 15 interviews with mobile app developers were on average 35 minutes in length and participants were asked to reflect on five main themes: target clients and the activities of their firm; app innovation and diffusion methods; the app industry in their country; the national and international app market; and the potential of developing apps for local social interests, development purposes or marginalised groups. In addition to the interviews with mobile app developers, two interviews were conducted with representatives of Non-Governmental Organisations (NGOs) involved in digital inclusion projects and one interview with a representative of a business incubator that had worked with mobile app firms. These interviews were slightly longer (45 minute average) and explored themes relating to the mobile app markets and industries as well as the challenges and opportunities for local development-oriented apps.

\section{Context - Mobile media in Argentina and Bolivia}

Focussing on two Latin American countries with differentiated socioeconomic situations allows for comparison of the circumstances that shape app developers' targets and activities. In terms of economic indicators, Argentina is considered an 'Upper-Middle Income' country and Bolivia, a 'Lower-Middle Income' country (OECD, 2013). In terms of social indicators, the human development index is classified as 'very high' in Argentina and 
as 'medium' in Bolivia (UNDP, 2013). International development aid flows are higher to Bolivia than Argentina, comprising $13.8 \%$ and $0.2 \%$ of the gross capital formation respectively (World Bank, 2014). While both nations were built on myths of European identity through colonisation, the contexts of postcolonial nation building vary. Bolivia's 2001 census revealed a $62 \%$ indigenous majority. ${ }^{2}$ With the election of Evo Morales to office in 2005, the term 'decolonisation' spread through government discourse, developing a political and discursive structure in which previously marginalised voices could be valued (Howard, 2010). On the other hand, the 3\% indigenous population in Argentina continues to face discrimination via a social and political context which invisibilises indigenous existence, with recent years seeing increasing indigenous mobilisations for local ownership over media production (Author).

Recent media policies in both countries recognise cultural diversity and include objectives relating to the expression of regional and local cultures as well as democratic inclusion in the information society. Argentina's Audiovisual Communication Services Law of 2009 ('SCA Law') and Bolivia’s General Law of Telecommunications and Information and Communication Technologies of 2011 ('Law 164') restrict corporate monopolies of radio and television broadcasting and allocate frequencies to communitarian organisations. However, the democratisation of new media platforms is largely neglected. The SCA Law defines audiovisual communication services as television and radio broadcasting. Policy on new media in Argentina is found in the Law on the Promotion of Software (2004), which 
adopts neoliberal aims: the government-funding agency FONSOFT prioritises firms involved in exportation or with internationally recognised quality certificates. Alternatively, Bolivia's Law 164 specifies areas of content and application development that receive prioritised funding, all of which relate to social and economic development issues within the country. Thus, while government-funding priorities in Bolivia present a local development focus, those in Argentina intend to amplify the software industry's international presence, which by UNCTAD’s classification (2012) has 'high export intensity.'

As seen in Table 4, mobile telephony is the most prevalent bidirectional communication technology in both countries. Mobile-broadband penetration, while minimal, more than doubled between 2010 and 2012 in both countries (ITU, 2013a), where 500 MB of prepaid mobile-broadband is $51 \%$ cheaper in Bolivia and 33\% cheaper in Argentina than the monthly fixed-line broadband fee (ITU, 2013b).

The mobile network operators Viva in Bolivia and Movistar in Argentina offer online app stores where users can purchase apps with phone credit, enabling app sales to users without credit cards. However, these stores offer minimal apps and do not feature locally specific contents or apps by in-country developers. ${ }^{3}$ As of yet, developers in Bolivia cannot sell apps on the Google Playstore and this service in Argentina was set to be suspended in 2013 before Google backtracked on the decision (La Gaceta, 2013). Table 5 provides a snapshot of where the most popular free apps on the Android and iOS stores are 
developed, comparing Bolivia and Argentina alongside three of the largest mobile app markets according to App Annie (2014a). Apps included in the table were in the top 10 most downloaded free apps in either the iOS or Android stores at four intervals in March 2014. In the big markets of China, Japan and the USA, developers within the country published the most popular apps. However, developers in the USA and Europe were the biggest sellers in the Argentinean and Bolivian stores: of the 21 apps developed in 'Other' locations in both stores, 15 were from European Union countries and only two from other Latin American countries. These download patterns suggest that while developers in large app markets effectively use the iOS and Android stores to target and distribute apps to general public users in their country, this is not the case for Argentinean or Bolivian developers.

\section{Results}

\section{Overview of mobile app firms}

Results from the website review are gathered in Table 6. The international app market was important for firms in both countries, but those in Bolivia were more likely to target the national market only. The majority of firms in both countries developed custom projects, whether for businesses, public institutions or NGOs. Commercial businesses—such as multinational corporations, banks and restaurants—-were the most important target clients in both countries and the majority of firms in Argentina only worked for business clients. Firms in Bolivia were more likely to target public institutions and NGOs, particularly those with a national target. Of the firms that only targeted the national market, 57\% in Bolivia 
and $7 \%$ in Argentina targeted NGOs and $72 \%$ in Bolivia and 20\% in Argentina targeted public institutions.

The majority of firms in both countries developed marketing apps and/or business management tools (95\% in each country). A significant number of these firms exclusively developed apps of these two types: 43\% in Bolivia and 61\% in Argentina. Marketing apps were particularly important for the reviewed businesses in Argentina and 15\% only developed apps for marketing purposes. Educational apps were more important for Bolivian developers and were related to the NGO target: all firms that developed educational apps in Bolivia targeted NGOs.

In line with the importance of enterprise apps, most firms promoted their corporate orientation. These websites included speak of business productivity or customer relations in their company values or mission statements. Often alongside corporate speak, a number of firms also promoted their innovativeness, in this case, valorising creativity and novelty. Firms that marketed apps on app stores tended to be more interested in promoting their innovativeness.

Firms in Bolivia were more likely to promote their interest in the national context or in digital inclusion. The latter included speak of corporate responsibility projects, such as community oriented digital literacy workshops, or the social or economic benefits of communication technologies. The higher level of interest in inclusivity and the local context in Bolivia relates to the greater market presence of NGOs and public institutions: 
$80 \%$ of firms that promoted their interest in the local context or social inclusion targeted public institutions and $60 \%$ of that same group targeted NGOs.

\section{Perspectives on the mobile app industry}

\section{Argentina: Mobile marketing and the lucrative international target}

Developers in Argentina explained they targeted users or businesses internationally as it was more lucrative and prestigious; most considered the Argentinean app market too small to warrant interest. All participants had either worked internationally or intended to expand their target. Those that targeted business clients explained it was important to have partnering agencies abroad to be successful. Three participants worked almost exclusively with marketing agencies, and even when the agencies were located in Argentina, the final clients were often abroad.

Participants that targeted business clients explained they had no contact with final users or even final clients in many cases as they worked for intermediary agencies. The clients would usually have an idea of the product they wanted and there was little room for innovation: 'it's not really that innovative, we replicate things we see on the web.' Likewise, most participants had not done any market research into the interests of users as they responded to custom requests from companies. However, one participant who presently targeted network operators and media companies within Argentina had done some market research in order to develop a news app platform.

User involvement and feedback was considered more important for own-source projects than custom-design work. Two participants had created Web 2.0 second screen apps 
through own-source funds: one used trial runs on the app store to receive feedback and the other had created mock events with user groups. While market research was not important for custom-design projects, those that created apps for the app stores paid attention to user interests: they considered new appropriations of technologies, talked to their friends and families, and looked to the ways that youth were using phones for inspiration. These participants, however, were generally not interested in appropriations of mobile technologies by user groups in Argentina, as they targeted the app store market internationally.

Most participants felt that app store sales were not an effective business model—they explained it was too difficult to popularise an app or even get it seen—and those that did market apps on the app stores felt it was important to target users outside of Argentina. Only one participant targeted app stores exclusively, having found success through in-app sales. Two other participants had sold apps on the app stores before but found more profit in sales to business clients.

There were only three cases where participants had targeted app store users in Argentina. One participant had developed an app version of an Argentinean card game. Even though the app was very successful, hitting number one in Argentina, they did not find it sufficiently financially rewarding: 'We wanted to try the [Argentinean] market, see how big it is, but it was so small that we didn't care anymore about it.' Two participants had posted free apps on the Playstore aimed at the interests of Argentinean users. One was the trial- 
run version of a second screen app for football matches. The participant explained that the app was very popular but that they would expand their market focus to Brazil and Europe before selling the app. The other free app arose from personal interest and was a way to showcase the developer's work: a 'cacerolazo' app for the Playstore, developed around the time that this form of social protesting was big in Argentina. Apart from this app, this participant developed what he considered 'general' social networking apps for the international market, which proved to be most popular in Indonesia. Another participant also stressed the importance of creating 'neutral' products for the app stores. In this case, the main target was users in United States and most of the apps were only available in English.

None of the participants had developed apps for special interest groups within Argentina as they felt there was no market in this area. Two participants had received funding from the government software fund FONSOFT, which they were using to extend their target internationally. Participants were not aware of any government-funded app projects that specifically targeted users in Argentina and none of the participants considered NGOs an interesting client. Most participants had never been contacted by an NGO. One participant had been asked by an NGO to do a project but declined: 'NGOs don't pay.'

\section{Bolivia: The restricted local app market and the importance of NGO funding}

App developers in Bolivia felt there was no market interest for mobile apps within the country. Those that targeted the national market focused on non-mobile services. The business incubator interviewed in this study estimated there were less than 10 mobile apps 
that had been developed for the Bolivian market, including those not distributed over app stores. While all developers invited to interview claimed to develop mobile apps on their website, two participants that targeted the national market had not yet developed apps for clients. One was already licensed in iOS and Android; he had received some inquiries about mobile apps, but in the end, his clients in Bolivia could not afford them. The other planned to target the international app market the following year.

However, two participants had developed mobile apps for businesses in Bolivia. One was for a bank and it was their first mobile project. The other was for an internationally focused publicity agency; in this participant's experience, it was the only time that a company in Bolivia had inquired about a mobile app and the final clients were outside of Bolivia. According to participants, a main factor for the restricted mobile app market in Bolivia relates to the high cost and low penetration of the Internet, as well as the lack of an internet buying culture. Participants that targeted clients within Bolivia typically provided non-mobile services to businesses, NGOs or government institutions. These participants felt it would be difficult to target the international market; reasons included language barriers and the lack of connections with agencies abroad. From the perspective of the business incubator, the software industry is in a nascent phase in Bolivia and developers lack the confidence to produce products at an international level. Only two participants had partaken in app store sales and both targeted users in the United States through the iOS Store. According to these participants, their ideas for innovation generally came from their 
surroundings, from things they noticed in their cities or from conversations with friends and families; however, they explained that as final users in Bolivia did not have credit cards or access to app stores, there was no market for apps about Bolivian specific topics. Likewise, they often looked to what was popular on the app stores in United States. Most participants, including those that worked for business clients, had carried out some form of market research. Three developers that targeted national businesses had identified the needs of sectors in Bolivia and developed platforms or apps with own-source funds. Yet, another participant explained that when he worked for a large software firm they did no market research and had no contact with final users as they focused on custom-design projects. On the other hand, the NGO representative explained they worked closely with teachers and students to create educational apps, implementing trial projects in the classrooms and directly inputting student ideas.

Most participants had developed or would be interested in developing projects for rural communities or special interest groups in Bolivia and four felt that NGOs provided an interesting target market. One participant, apart from his work in a software firm, developed his own projects and attended start-up weekends in Bolivia where sponsors at times prioritised projects relating to issues within the country. Another developer was connected to an NGO network in Bolivia which supported digital inclusion projects and his firm had offered digital literacy workshops in rural communities. This network enabled them to make contacts with NGO clients. In this participant's experience, external NGOs, 
and not the government, fund the majority of software projects in Bolivia that address local users' needs. A number of participants, including the NGO representative and business incubator, criticised the government's failure to support software projects. Two developers noted that there was an information gap in Bolivia: they felt there was a lack of apps and online information about events and places in Bolivia.

\section{Discussion and conclusion}

\section{Business clients or international users}

Reviewed firms in both countries tended to partake in one or more of three genres of app projects. First: custom-design marketing apps. These apps were typically developed for commercial businesses abroad_-often via a marketing agency—and involved little contact with final users and no market research. These projects were more important for firms in Argentina. While participants in Bolivia explained they lacked international contacts, those in Argentina felt that marketing apps were secure, lucrative work with no upfront investment. Second: business management tools for corporate entities or public institutions. These tools were either custom-designed or in some cases developed with own-source funds, based on market research of a specific sector. These projects were the most important activity for firms in Bolivia, but the focus was typically non-mobile services as there was minimal demand for mobile apps in Bolivia. Third: social networking, entertainment or utility apps for general public users, marketed over platform providers' app stores. For these projects, developers paid attention to user appropriations. 
Few developers in this study marketed apps over app stores and if they did, the target was almost exclusively international, often catered to users in United States. Developers in Argentina felt it was important to target the more lucrative international markets due to the costs involved in developing and marketing apps on app stores. Developers in Bolivia felt that users in their country were not able to access or purchase contents on online app stores. In effect, the few firms in either country that targeted general public users were almost exclusively interested in mobile use trends at the international level.

\section{What about the local user?}

Outside of custom-design projects and the international app store target, there were some contexts where the local public was of interest, particularly in Bolivia. NGOs were considered an interesting and lucrative target market for firms in Bolivia, and likewise, there was more interest in developing projects for local user groups. Firms in Bolivia were more likely to promote their local orientation or interest in the social benefits of technologies on their websites and some participants had explored investing own-source funds in projects that targeted rural communities. Few firms in Bolivia had developed mobile apps for NGOs as of yet, but developers were interested in exploring local interests and app-based projects with a social development angle based on experiences they had working on other software or web projects for NGOs.

In Argentina, developers were not drawn to local interests because of development aid funding, but in a few cases for the sake of professional growth. Whereas the app store market in Argentina was not considered large enough to target for financial ends, there 
were enough users to substantiate an effective trial run: two participants had produced free apps with Argentinean specific content for the app stores, one to receive feedback on an app platform and the other to showcase their work. In both cases, the developers had identified an app that would be of interest for users in their country, yet neither planned to expand in this area or perform future trial runs of this type.

\section{Concluding remarks}

Communication policies in Argentina and Bolivia aim to democratise media production and promote the expression of national or regional cultures. Mobile telephony is the most prevalent bidirectional communication technology in both countries and while mobile communication is increasingly centred on apps, the most popular apps in Argentinean and Bolivian app stores are produced in the United States or Europe. Our research explored the targets, activities and perspectives of mobile app developers to analyse the conditions that connect or disconnect developers from the interests of publics within their country. That is, we aimed to sketch hypotheses on the political economy of commercial app production, looking at how developers are positioned within a mobile app ecosystem increasingly monopolised by companies in the United States.

Government regulations on software services in both countries specify funding priorities, but with opposing aims: locally oriented solutions are prioritised in Bolivia while Argentina's FONSOFT aims to support the international presence of the software and service industry. We found more firms in Bolivia focused on the national market, yet this did not simply reflect government-funding priorities. The software and service industry in 
Bolivia is in a nascent state and developers lacked international contacts to succeed in exports. The mobile app industry is particularly restricted as there is little demand for enterprise apps at the national level and no adequate marketing channels for general public users. Despite these blocks in the Bolivian market, there was greater interest in developing apps for local user groups or for social development purposes than in Argentina. While NGOs were more important clients in Bolivia, firms in Argentina were more likely to have established relations abroad and preferred work for international marketing agencies.

In both countries, app distribution channels disconnected developers from users in their country. App stores hosted by major platform providers were rarely used directly by developers to distribute apps to in-country users. Moreover, outside of these major app stores, commercial developers were not distributing apps to the public by any other method. The small app stores provided by network providers in Argentina and Bolivia do not feature apps by local developers and participants had not considered app sales to the public beyond the major platform providers' stores. Moreover, participants expressed difficulties in marketing apps on platform providers' stores and over $90 \%$ of the analysed firms in both countries focused on custom-design projects for business clients. In effect, the majority of apps available to general public users in Argentina and Bolivia that have been developed in-country are marketing apps contracted and diffused over app stores by commercial businesses — with no research into the interests of final users by developers. 
We arrive at two main hypotheses. First, development aid funding can foster an environment where app developers in small markets are interested in the needs of publics within their country even when not directly related to work for NGOs. Development cooperation has faced criticism for failing to overturn—or even reinforcing-rooted power asymmetries that generate contexts of marginalisation (see Escobar 1991). Our research suggests that the presence of development aid funding foments an imaginary of an alternative, local app market among developers, peaking their interest in the app needs of local and marginalised groups or in showcasing locally oriented projects.

Second, platform providers' international app stores may block alternative distribution channels that favour local markets by setting a standard method of distribution. Already in 1981, Fejes pointed to the role of systems and institutions within countries as well as the interaction between internal and external factors in the formation of globally dominant media systems. Locally produced contents are not necessarily counter-hegemonic, but may reinforce or reproduce mainstream trends (García-Canclini, 1998). In our research, the prominence of international distribution platforms left developers either excluded from marketing apps to the public or intentionally copying dominant themes to succeed in more lucrative and larger markets. Where communication policies such as the SCA Law in Argentina set out regulations to encourage the diffusion of locally relevant contents, our research brings question to whether similar forms of governance should be applied to app distribution platforms. 
Regulations on local content quotas have been used for other types of media to foster local production and strengthen creative industries (see Baughn \& Buchanan, 2001). In addition, alternative app distribution platforms in other developing contexts, such as overthe-counter app sales, have enabled developers to market apps to local users, unlocking demand for local contents (see Kathuria and Srivastav, 2014: 35-6). Along these lines, public policy could help generate space for developers to market apps to in-country users by designating funding to alternative app distribution platforms, or potentially, by setting quotas of locally developed apps on the national portals of platform providers' stores.

While these conclusions specifically reflect the reviewed firms in Argentina and Bolivia, we suggest further research would be of interest on the role of development aid funding and app stores in orienting app developers' targets in developing world economies.

\section{Notes}

1. Of the 42 contributions on mobile apps in the previous two Information Communication Technology and Development Conferences (ICTD 2012 and 2013) and Mobile Communication and Development Conferences (M4D 2012 and 2014), 27 concern Africa, 14 concern Asia, and one concerns Latin America.

2. In the 2012 Census, $42 \%$ of the population self-identified as indigenous. The significant variance from the 2001 Census reflects a change in the question (see Albó, 2012). 
3. The 66 apps in Movistar's store are provided by three international gaming firms and largely relate to games and films produced in United States (see Movistar, 2014). Viva's store_-accessed on an Android device in July 2014_offered 896 apps covering a variety of internationally oriented contents (largely relating to United States or India), all labelled in English.

\section{References}

Albó, X. (2012). Censo 2012 en Bolivia: Posibilidades y limitaciones con respecto a los pueblos indígenas. Tinkazos 15(32): 33-45.

Alexa (2014) The top 500 sites on the web. Available at: http://www.alexa.com/topsites (accessed 11 May 2014).

App Annie (2014a) App Annie index: 2013 retrospective. Report, January.

App Annie (2014b) Store stats. Available at:

http://www.appannie.com/apps/ios/top/?device=iphone (accessed 19 April 2014).

Apple (2014) Choosing an iOS developer program. Available at:

https://developer.apple.com/programs/start/ios/ (accessed 11 May 2014).

Basole RC and Karla J (2012) Value transformation in the mobile service ecosystem: A study of app store emergence and growth. Service Science 4(1): 24-41. 
Bationo-Tillon A, Sangaré L and Ledunois V (2014) Mismatches between occidental designers and mobile phone users from West Africa. In: Proceedings of the 4th International Conference on M4D. Karlstad University Studies, 95-106.

Baughn, C., \& Buchanan, M. (2001). Cultural protectionism. Business Horizons, 44(6), 5-15.

Beltrán LR and Fox de Cardona E (1980) Comunicación Dominada: Estados Unidos en los Medios de América Latina. México: Nueva Visión.

Bolaño C and Mastrini G (2001) Economía política de la comunicación: Un aporte marxista a la constitución del campo comunicacional. EPTIC 3(3), 58-78.

García-Canclini N (1998) La globalización en pedazos: integración y rupturas en la comunicación. Diálogos 51: 9-23.

Castells M (2001) The Internet Galaxy: Reflections on the Internet, Business and Society. Oxford University Press.

Castells M (2012) Networks of Outrage and Hope: Social Movements in the Internet Age. Cambridge: Polity Press.

De Valle Rojas C (2009) La concentración de la estructura de medios en Chile: Conglomerados, emergencia y políticas. In Actas del VII Congreso Internacional ULEPICC. Madrid, 117-25. 
Dey B, Newman D and Prendergast R (2011). Analysing appropriation and usability in social and occupational lives: An investigation of Bangladeshi farmers' use of mobile telephony. Information Technology and People 24(1): 46-63.

Donner J (2010) Framing M4D: The utility of continuity and the dual heritage of 'mobiles and development.' The Electronic Journal on Information Systems in Developing Countries 44(3): $1-16$.

Escobar A (1991) Anthropology and the Development Encounter: The Making and Marketing of Development Anthropology. American Ethnologist 18 (4): 658-682.

Fejes F (1981) Media imperialism: an assessment. Media, Culture and Society 3(3): 281-9.

Fuchs C (2009) Information and communication technologies and society: A contribution to the critique of the political economy of the internet. European Journal of Communication 24(1): 69-87.

Goggin G (2011) Global Mobile Media. New York: Routledge.

Google (2013) Our Mobile Planet: Argentina Understanding the Mobile Consumer. Report, May. 
Google (2014) Supported locations for developer and merchant registration. Available at: https://support.google.com/googleplay/android-developer/table/3539140?hl=en (accessed 11 May 2014).

Greene JC, Caracelli VJ and Graham WF (1989) Toward a conceptual framework for mixed-method evaluation designs. Educational Evaluation and Policy Analysis. 11(3): 255-74.

GSMA (2013) Economía Móvil América Latina. Report.

Gurumurthy A (2010) From social firms to mobiles: Seeking a peg to hang a premeditated ICTD theory. ITID 6: 57-63.

Hellström J (2010) The innovative use of mobile applications in East Africa. Report for Sida Review, May.

Hindman M (2009) The Myth of Digital Democracy. Princeton University.

Howard R (2010) Language, signs, and the performance of power: The discursive struggle over decolonization in the Bolivia of Evo Morales. Latin American Perspectives 37(3): 17694.

Hwang JS, McMillan SJ and Lee G (2003) Corporate web sites as advertising: An analysis of function audience and message strategy. Journal of Interactive Advertising 3(2): 10-23. 
IDC (2013) Top Smartphone Operating Systems, Shipments and Market Share. Available at: http://www.idc.com/getdoc.jsp?containerId=prUS24257413 (accessed 11 May 2014).

INDEC (2012) Censo 2010. Instituto Geográfico Nacional.

ITU (2013a) World Telecommunication/ICT Indicators database. Geneva.

ITU (2013b) Measuring the Information Society. Geneva.

Jenkins H, Ford S and Green J (2013) Spreadable Media: Creating Value and Meaning in a Networked Culture. New York University Press.

Kathuria BR and Srivastav S (2014) The Indian App Ecosystem. Report for the Indian Council for Research on International Economic Relations.

Khalaf S (2014) Apps Solidify Leadership Six Years into the Mobile Revolution. Available at: http://www.flurry.com/bid/109749/Apps-Solidify-Leadership-Six-Years-into-theMobile-Revolution\#.U2-Yn1e9J2A (accessed 11 May 2014).

Kumar V and Svensson J (eds) (2012) Proceedings of M4D 2012. Karlstad University Studies.

La Gaceta (2013) Google Recapacita y Aceptará Aplicaciones Pagas de Desarrolladores Argentinos. Available at: http://www.lagaceta.com.ar/nota/550294/tecnologia/google-recapacitaaceptara-aplicaciones-pagas-desarrolladores-argentinos.html (accessed 14 May 2014) 
Loader BD and Mercea D (2011) Networking democracy? Information, Communication and Society 14(6): 757-69.

Mansell R (2004) Political economy, power and new media. New Media and Society 6(1): 7483.

Martín-Barbero J (2002) Medios y culturas en el espacio latinoamericano. Iberoamericana 2(6): 89-106.

Mastrini G (2005) Twenty years mean nothing. Global Media and Communication 1(3): 273-88.

Mastrini G and Becerra M (2011) Estructura, concentración y transformaciones en los medios del Cono Sur latinoamericano. Comunicar 18(36): 51-9.

Mattelart A (1974) La Cultura como Empresa Multinacional. Buenos Aires: Editorial Galerna.

Meroño-Cerdan AL and Soto-Acosta P (2005) Examining e-business impact on firm performance through website analysis. International Journal of Electronic Business 3(6): 58398.

Movistar (2014) Tienda de Juegos. Available at: http://tiendajuegos.movistar.com.ar/Default.aspx (accessed 12 July 2014).

Moyo D (2007) Alternative media, diasporas and the mediation of the Zimbabwe crisis. Ecquid Novi 28(1-2): 81-105 
Ngugi B, Pelowski M and Ogembo JG (2010) M-PESA: A case study of the critical early adopters' role in the rapid adoption of mobile money banking in Kenya. The Electronic Journal on Information Systems in Developing Countries 43(3): 1-16.

Niang I, Scharff C and Wamala C (eds) (2014) Proceedings of the 4th International Conference on M4D. Karlstad University Studies.

OECD (2013) DAC List of ODA Recipients. Available at: http://www.oecd.org/dac/stats/daclistofodarecipients.htm (accessed 12 May 2014).

Padovani C and Tuzzi A (2004) The WSIS as a world of words: Building a common vision of the Information Society? Continuum 18(3): 360-79.

Pickard V (2007) Neoliberal visions and revisions in global communications policy from NWICO to WSIS. Journal of Communication Inquiry 31(2): 118-39.

Rodríguez C (2009) De medios alternativos a medios ciudadanos: trayectoria teórica de un término. Revista Folios: 13-25.

Schwartz D (2014) The future of political economy of media: A conversation with Dr. Robert W. McChesney. Journal of Communication Inquiry 38(3): 173-83.

Snider J, Hill RP and Martin D (2003) Corporate social responsibility in the 21st Century: A view from the world's most successful firms. Journal of Business Ethics 48: 175-87. 
Srinivasan R (2012) Re-thinking the cultural codes of new media: The question concerning ontology. New Media and Society 15(2): 203-23.

Statista (2014) App Stores: Cumulative Number of Apps Downloaded as of July 2013. Available at: http://www.statista.com/markets/424/topic/538/mobile-internet-apps// (accessed 23 May 2014).

UNCTAD (2012) Information Economy Report: The Software Industry and Developing Countries. New York: United Nations.

UNDP (2013) Human Development Report: The Rise of the South. New York: United Nations.

Walton M and Donner J (2012) Public access, private mobile: The interplay of shared access and the mobile Internet for teenagers in Cape Town. Global Impact Study Series, October.

World Bank (2014) World Dependency Indicators: Aid Dependency. Available at: http://wdi.worldbank.org/table/6.11 (accessed 28 April 2014).

WSIS (2005) Tunis Agenda for the Information Society. United Nations.

Zittrain J (2008) The Future of the Internet and How to Stop It. New Haven: Yale University Press. 
Table 1: Top ten publishers of game apps and apps outside of games in 2013: Worldwide iOS and Android Playstore downloads

\begin{tabular}{|c|c|c|c|c|}
\hline Rank & Game Publisher & Headquarters & App publisher & Headquarters \\
\hline 1 & Electronic Arts & United States & Google & United States \\
\hline 2 & Gameloft & France & Facebook & United States \\
\hline 3 & Rovio & Finland & Sungy Mobile & China \\
\hline 4 & King & United Kingdom & Outfit 7 & Cyprus \\
\hline 5 & Tiny Piece & China & Microsoft & United States \\
\hline 6 & Disney & United States & WhatsApp & United States \\
\hline 7 & Storm8 & United States & Apple & United States \\
\hline 8 & Imangi & United States & Tencent & China \\
\hline 9 & LINE & Japan & LINE & Japan \\
\hline 10 & Glu & United States & Baidu & China \\
\hline
\end{tabular}

Source: reproduced from App Annie, 2014a 
Table 2: Dimensions of the website review

\begin{tabular}{lll} 
Dimensions & Analysed characteristics & $\begin{array}{l}\text { Where data was extracted on } \\
\text { the websites }\end{array}$ \\
\hline Services & Mobile apps only; Mobile apps and & Product lists, explanations of \\
& other web or software services & activities \\
\hline Regional Target & Foreign markets only; National and & Client lists, explanations of \\
& foreign markets; National market & activities \\
& only & \\
\hline Target Client & Businesses; Public institutions; & Client lists, explanations of \\
& NGOs; General public & activities \\
\hline Mobile App & Marketing; Business management; & Product lists, explanations of \\
Types & Games; Social networking; Utilities; & activities \\
& Educational & \\
\hline Self-Promotion & Innovative; Corporate; Offshoring; & About us, mission statement, \\
Themes & Local orientation; Socially & vision and/or goals sections \\
& inclusive/beneficial &
\end{tabular}

Source: own elaboration 
Table 3: Overview of interview participants

\begin{tabular}{lll} 
Type of respondent & Argentina & Bolivia \\
\hline Mobile app developers (corporate firms) & 9 & 6 \\
NGOs & 1 & 1 \\
Business incubators & 0 & 1 \\
Total & $\mathbf{1 0}$ & $\mathbf{8}$ \\
\hline
\end{tabular}

Source: own elaboration 
Table 4: Key ICT indicators in Argentina and Bolivia

Indicators

Argentina

Bolivia

Households with computers $^{2}$

$48 \%$

$26 \%$

Households with Internet $^{a}$

$56 \%$

$10 \%$

Households with fixed-line telephony ${ }^{\mathrm{b}}$

$56 \%$

$20 \%$

Households with mobile telephony

$86 \%$

$76 \%$

Mobile subscriptions per 100 habitants $^{\mathrm{a}}$

152

90

Active mobile-broadband subscriptions per

12

7

100 habitants $^{\mathrm{a}}$

$3 G$ network coverage ${ }^{c}$

$41 \%$

$15 \%$

\footnotetext{
${ }^{a}$ Data from 2012 (ITU, 2013a).

${ }^{\mathrm{b}}$ Bolivia data from 2009 (ITU, 2013a). Argentina data from 2010 (INDEC, 2012).

${ }^{\mathrm{c}}$ Data from 2013 (GSMA 2013).
} 
Table 5: Development location of top free apps of March 2014: iOS and Android stores in Argentina, Bolivia, China, Japan and the USA

\begin{tabular}{l|lllll}
\hline Developer & \multicolumn{5}{|c}{ App store location } \\
location & Argentina & Bolivia $^{\mathrm{b}}$ & China & Japan & USA \\
\hline Argentina & 0 & 0 & 0 & 0 & 0 \\
Bolivia & 0 & 1 & 0 & 0 & 0 \\
China & 0 & 1 & 31 & 0 & 1 \\
Japan & 4 & 2 & 0 & 27 & 3 \\
USA & 13 & 12 & 3 & 2 & 18 \\
Other & 14 & 7 & 4 & 1 & 10 \\
\hline
\end{tabular}

a 'Top apps' refers to the apps which ranked in the top 10 position by daily ranking statistics on March 7, 14, 21 and 28. Apps that appear in both the Android and iOS stores are only counted once.

${ }^{\mathrm{b}}$ Data on Bolivia only shows iOS downloads as Android store data is not available.

Source: own elaboration based on data extracted from App Annie, 2014b. 
Table 6: Targets and activities of mobile app developers: Content analysis of reviewed websites

Argentina Bolivia

\section{Regional target}

National market only

$15(11 \%)$

$7(23 \%)$

Foreign market only

$6(5 \%) \quad 4(19 \%)$

Both markets

$112(84 \%)$

$20(65 \%)$

Valid observations ${ }^{a}$

133

31

\section{Marketing channel}

Custom projects only

$134(87 \%)$

$33(92 \%)$

App stores only

$4(3 \%)$

$0(0 \%)$

Both channels

$15(10 \%)$

$3(8 \%)$

Valid observations ${ }^{a}$

153

36

\section{Target clients $^{\mathrm{b}}$}

Businesses

$143(95 \%)$

$28(93 \%)$

Businesses only

$88(57 \%)$

$11(36 \%)$

Public institutions

$37(25 \%)$

$16(53 \%)$

Public institutions only

$1(1 \%)$

$1(3 \%)$

NGOs

$12(8 \%)$

$12(40 \%)$

NGOs only

$0(0 \%)$

$0(0 \%)$

Valid observations ${ }^{a}$

150

30 


\begin{tabular}{lll}
\hline Types of mobile apps developed $^{\mathrm{b}}$ & & \\
\hline Business management & $92(64 \%)$ & $16(76 \%)$ \\
Marketing & $109(76 \%)$ & $15(71 \%)$ \\
Social networking & $27(19 \%)$ & $8(21 \%)$ \\
Utilities & $35(25 \%)$ & $3(8 \%)$ \\
Games & $18(13 \%)$ & $1(3 \%)$ \\
Educational & $5(4 \%)$ & $4(11 \%)$ \\
Valid observations & 143 & 21 \\
\hline
\end{tabular}

\section{Self-promotion theme ${ }^{\mathrm{b}}$}

\begin{tabular}{lll}
\hline Corporate & $124(74 \%)$ & $31(82 \%)$ \\
Innovative & $52(33 \%)$ & $8(21 \%)$ \\
Offshoring & $14(9 \%)$ & $3(8 \%)$ \\
Social inclusion/benefit & $7(5 \%)$ & $7(18 \%)$ \\
Local orientation & $1(2 \%)$ & $7(18 \%)$ \\
None & $18(12 \%)$ & $4(11 \%)$ \\
Valid observations & 157 & 38
\end{tabular}

${ }^{a}$ We only report cases with sufficient information on the analysed dimension.

${ }^{\mathrm{b}}$ Non-exclusive categories.

Source: own elaboration 